\title{
Influence of the mining depth factor on accuracy of the forecast of the earth's surface subsidence in Kuzbass
}

\author{
Sergey Kulibaba ${ }^{1 *}$ and Natalia Miletenko ${ }^{1}$ \\ ${ }^{1}$ Institute of Comprehensive Exploitation of Mineral Resources Russian Academy of Sciences \\ (IPKON RAS), 111020, Moscow, 4, Kryukovsky tupik, Russian Federation
}

\begin{abstract}
Based on the results of the forecast of the earth's surface deformations in the zone of influence of underground mining, measures are being developed to reduce the degree of negative man-made influence on undermined buildings, structures and natural objects. Changes in mining conditions affect the decrease in the accuracy of existing forecasting techniques. For example, under the conditions of Kuzbass, the actual earth's surface subsidence can in a great measure (by 15-25\%) exceed the predicted values. Research has shown that one of the factors affecting the source of error is the depth of mining. As a result of the research, a relationship is obtained between the value of the error in calculating the maximum earth's surface subsidence and the average depth of mining, and a method for adjusting the calculation method is proposed. Key words: underground mining of coal seams, the earth's surface subsidence, forecast, error, analysis of influencing factors, correction method.
\end{abstract}

\section{Introductionon}

The forecast of the earth's surface deformations from the influence of planned mining is one of the most important stages of solving the problem of rational extraction of minerals from the bowels. Based on its results, measures are being developed to reduce the degree of negative man-made influence on objects located in the undermined territories. Therefore, improving the accuracy of such a forecast is an actual scientific and practical task. Changing the conditions of underground mining of mineral deposits leads to a decrease in the reliability of the forecast of the stress-strain state of the undermined rock massif. In this regard, in order to successfully solve the problem of integrated development of reserves and rational planning of mining [1-5], special attention is paid to improving methods for calculating the earth's surface deformations [6-9].

Underground mining of coal seams in most cases is carried out in descending order, both within the same layer, and in the formation. As a result, there is a steady tendency to increase the depth of mining, which is one of the most important factors affecting the magnitude of deformations of the rock mass and the earth's surface [9]. In this regard, the

\footnotetext{
*Corresponding author: ksb52@mail.ru
} 
topicality of studies of the influence of this factor on improving the accuracy of prediction of rock movement parameters is constantly increasing.

\section{Disadvantages of the existing method}

Calculation of the predicted of the earth's surface deformations over the mining coal seams in the Russian Federation is performed in accordance with the methodology regulated by the methodological document [10]. Based on the results of this calculation, the degree of influence of mining operations on the condition of buildings, structures and natural objects that situated into the zone of displacement is estimated, and various protection measures are designed to minimize the negative consequences of mining.

Practical experience shows that at modern depths of mining coal seams, this calculation method gives an inaccurate forecast of the earth's surface subsidence. This is because for more than 20 years since the publication of this document [10], the forecasting methods included in it are outdated and do not correspond to reality. Consider a specific example. At the mine named after Kirov (JSC SUEK-Kuzbass) is mining the Boldyrevsky coal seam, which since 2016 has been accompanied by surveying instrumental observations of the earth's surface movement, as a result of which its actual deformations from the influence of mining operations are determined. For the period from 2016 to 2018, this mining was carried out sequentially by three faces \# 2458, \# 2459 and \# 2460.

Figure 1 shows graphs of the earth's surface subsidence $\eta$ above these working faces. Comparing the subsidence curves obtained as a result of instrumental observations 1 with the curves calculated by the method of [10] 2, we can see that the forecast gives underestimated values relative to the actual ones. In other words, here we are dealing with an error of second kind, which can eventually lead to negative consequences for undermining objects on the earth's surface - from a violation of their operational capabilities up to an emergency situation.

Table 1 shows the conditions for mining faces \# 2458, \# 2459 and \# 2460 and the main parameters of the movement, affecting the amount of the earth's surface deformation.

A comparison of geological and mining conditions of these faces shows that almost all of their characteristics coincide. An exception is only the average depth of their mining under the observation station - in neighboring working areas it varies by $20-40 \mathrm{~m}$ (4-8\% of the average depth). However, despite these relatively small values, the forecast errors of maximum subsidence were $15-25 \%$, as can be seen from figure 1 and Table 1 . This fact allows us to conclude that the existing forecasting technique in the conditions under consideration requires adjustment in terms of taking into account the development depth parameter $H$.

\section{Theory}

In order to identify the source of errors in forecasting of the earth's surface subsidence over mine workings, we dwell in more detail on the methodology for calculating them [10]. The main parameter that underlies the calculation of all types of predicted deformations of the earth's surface without exception is the maximum subsidence $\eta_{m}$, which is determined by the formula:

$$
\eta_{m}=q_{0} \cdot m \cdot \cos \alpha \cdot N_{1} \cdot N_{2}
$$

where $q_{0}$ - relative maximum surface subsidence; $m$ - coal seam thickness, $m ; \alpha$ - seam angle; $N_{1}$ and $N_{2}$ - coefficients describing the degree of earth's surface undermining in the main sections of the displacement trough $\left(N_{1}-\right.$ across the strike and $N_{2}-$ along the strike of the seams). 
Table 1. Conditions for working out faces \# 2458, \# 2459 and \# 2460 and main parameters of the movement

\begin{tabular}{|l|c|c|c|}
\hline \multicolumn{1}{|c|}{ Parameters } & face \#2458 & face \#2459 & face \#2460 \\
\hline Year of mining & 2016 & 2017 & 2018 \\
\hline Seam thickness $m, \mathrm{~m}$ & 2.40 & 2.35 & 2.40 \\
\hline Seam angle $\alpha$, degree & 5 & 5 & 5 \\
\hline Face length $D, \mathrm{~m}$ & 300 & 300 & 300 \\
\hline Average depth of mining $H, \mathrm{M}$ & 457 & 479 & 500 \\
\hline Relative maximum surface subsidence $q_{0}$ & 0.826 & 0.825 & 0.825 \\
\hline Coefficients of earth's surface undermining: & & & \\
- across the strike of the seam $N_{1}$ & 0.628 & 0.613 & 0.600 \\
- along the strike of the seam $N_{2}$ & 1.000 & 1.000 & 1.000 \\
\hline Maximum surface subsidence $\eta_{m}, \mathrm{~m}:$ & & & \\
& 1.186 & 1.183 & 1.162 \\
- predicted $\eta_{m \_} p$ & 1.581 & 1.478 & 1.349 \\
- actual $\eta_{m \_} a$ & &
\end{tabular}

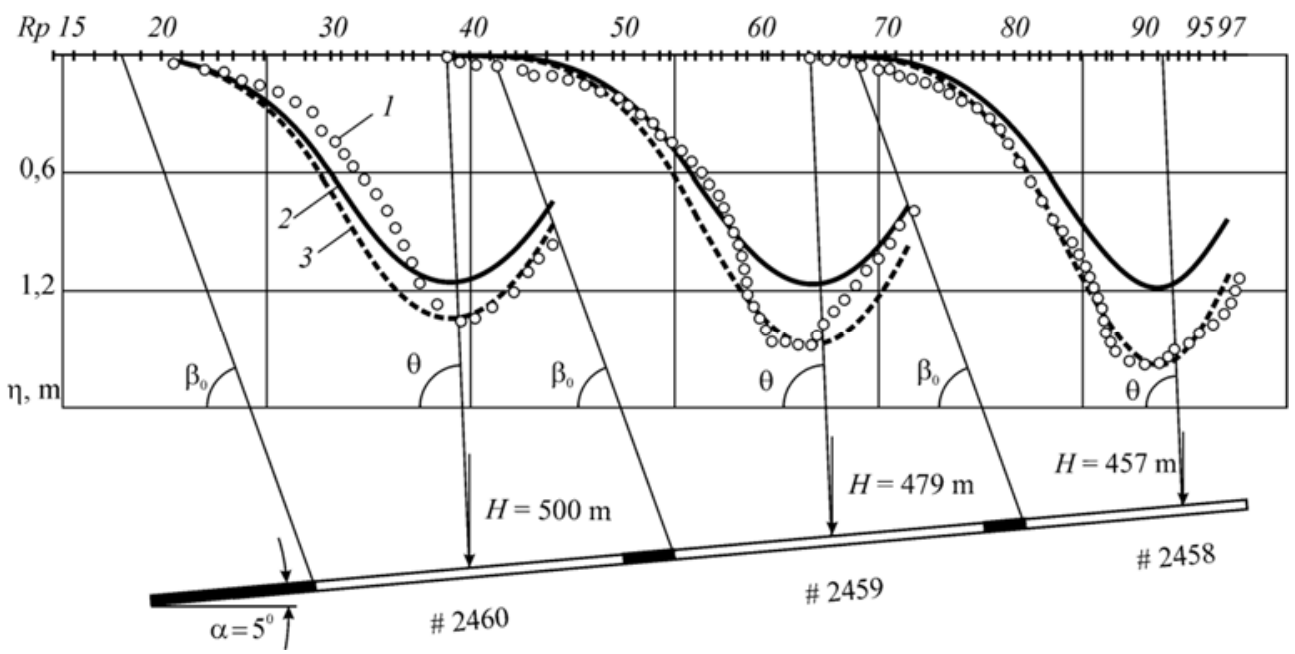

Fig. 1. Curves of the earth's surface subsidence over the faces \# 2458, \# 2459 and \# 2460: 1 - actual; 2 - calculated according to the methodology [10], 3 - reduced; $H$ - average mining depth

In this formula, the development depth $H$ is taken into account by the parameters $N_{1}$ and $N_{2}$, the values of which in [10] are tabulated in the interval $0.43 \leq N_{1(2)} \leq 1.0$ depending on the ratio of the size of the mined space $D_{1(2)}$ to the average mining depth $H$ in each of the two main sections of shift trough. The analysis showed that this tabular distribution for the conditions under consideration is approximated with a high degree of accuracy by a power polynomial of the 7 th degree:

$$
N_{1(2)}=a_{0}+a_{1}\left(\frac{D_{1(2)}}{H}\right)+a_{2}\left(\frac{D_{1(2)}}{H}\right)^{2}+\cdots+a_{7}\left(\frac{D_{1(2)}}{H}\right)^{7},
$$

where $a_{0}-a_{7}-$ empirical coefficients.

Considering the fact that in all three cases the coefficient of undermining of the earth's surface along strike $N_{2}$ is 1.0 (see Table 1), we can conclude that in the conditions under consideration, only coefficient $N_{1}$ changes with a change in depth $H$, and this is the source 
of error in the forecast. Obviously, the parameter $H$ included in formula (2) should be adjusted so that the predicted values of the maximum subsidence $\eta_{m}$ correspond to the actual values obtained by surveying instrumental observations.

To eliminate the cause of the forecasting error, we assume that the calculation of predicted subsidence will be correct if, in formula (2), to determine the coefficient $N_{1}$, instead of the actual value of depth $H$, some reduced parameter $H^{\prime}$ will be used.

The parameter $H^{\prime}$ can be determined for each of the three cases described above by jointly solving equations (1) and (2) with respect to $H=H^{\prime}$, assuming $\eta_{m}=\eta_{m_{-} a}$.

We study the dependence of the parameter $\Delta H$ on the actual depth $H$ :

$$
\Delta H=H-H^{\prime} \text {. }
$$

In figure 2 , where the dots show the $\Delta \mathrm{H}$ values for each of the considered lavas, you can see the trend of this value changing with depth. The analysis showed that this distribution can be described by an exponential function:

$$
\Delta H=k_{0}-\exp \left(k_{1}+k_{2} H\right)
$$

where $k_{0}, k_{1}$ and $k_{2}$ - coefficients equal for the considered conditions, respectively, 331.0, 0.3 and 0.01 .

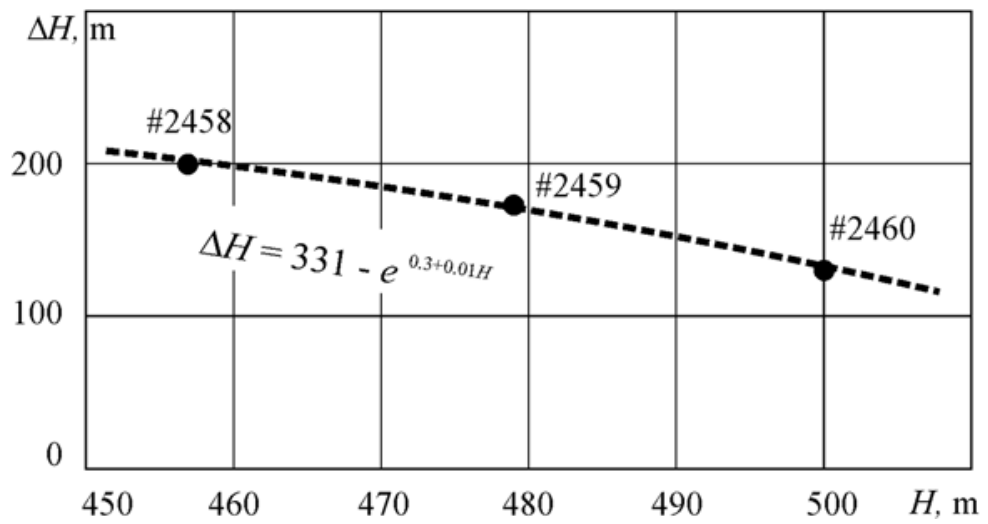

Fig. 2. The dependence of the parameter $\Delta H$ on the average depth of mining

In Figure 2, the position of the graph of this function is shown by a dashed curve.

\section{Results}

Thus, as a result of the studies, the forecast of the earth's surface subsidence over the mining coal seam under the conditions of Kuzbass is optimized. Its essence is to introduce amendments $\Delta H$, calculated by formula (4), to the average depth of mining when calculating the coefficient of earth's surface undermining according to the current method in the Russian Federation [10]. In this case, in the calculation formula $N_{1}(2)$, instead of the actual value of the depth $H$, the reduced depth $H^{\prime}$ should be used:

$$
H^{\prime}=H-\Delta H
$$

which will increase the forecast accuracy by $15-25 \%$, bringing the forecast results as close as possible to the observed actual data. Figure 1 shows that the graphs of subsidence calculated for each of the three faces under consideration by the proposed method (dashed lines) describe the actual earth's surface subsidence much more accurately than the curves obtained by the method [10]. 


\section{Conclusions}

The methodology for forecasting the earth's surface deformations during underground mining of coal deposits, regulated by the methodological document in force in the Russian Federation [10], has insufficient accuracy under the conditions of the Kuznetsk Basin, which can lead to low efficiency of the designed protection measures for buildings, structures and natural objects. In the process of research, it was revealed that the main cause of forecast errors is an incorrect account of the average depth of mining when determining the coefficient of the earth's surface undermining in the main section of the trough of the cross across the strike of the formation.

As a result of the studies, it was found that the forecasting error varies with the depth of mining. The relationship between these quantities is determined and a method for adjusting the methodology for calculating the maximum subsidence is proposed, which minimizes its error.

\section{References}

1. D. R. Kaplunov and D. N. Radchenko, GornyiZhurnal. 5, 28-33 (2016)

2. J. M. Galvin, Ground Engineering. Principles and Practices for Underground Coal Mining. Switzerland: Springer International Publishing, 684 p (2016)

3. K. N. Trubetskoy, S. V. Kornilkov and V. L. Yakovlev. GornyiZhurnal. 1, 15-19 (2012)

4. K.N. Trubetskoy, D.R. Kaplunov and M.V. Rylnikova, Journal of Mining Science. 48(4), 688-693 (2012)

5. S. Kulibaba and E. Esina, E3S Web of Conferences Electronic edition. Kemerovo, Russian Federation, October 3-5, 2018, 41 (2018)

6. I.A. Turchaninov, M.A. Iofis, E.V. Kasparyan, Basics of rock mechanics, (Leningrad: Nedra, 1989)

7. S.D. Viktorov, S.A. Goncharov, M. A. Iofis and V.M. Zakalinsky, Mechanics of rock movement and destruction, 360 p. (Moscow, 2019)

8. S. Kulibaba, Mine Surveying and Subsurface Use. 4, 32-34 (2019)

9. S. B. Kulibaba, Mine Surveying Bulletin. 1(128), 46-51 (2019)

10. Rules of protection of structures and natural objects from the harmful effects of underground mining on coal deposits / PB 07-269-98 (1998) 